\title{
Suppression of Cytokine-Inducible Nitric Oxide Synthesis During Intraperitoneal Meth A Tumor Growth
}

\author{
Oh-Deog KWON ${ }^{1,2,3) *}$, Chang-Yeol YIM ${ }^{4)}$, Kyu-Shik JEONG ${ }^{3)}$, Kyu-Yong JUNG ${ }^{5)}$, John R. McGREGOR ${ }^{1,2,6)}$, \\ Neil R. BASTIAN ${ }^{2)}$ and Wolfram E. SAMLOWSKI ${ }^{1,2,6)}$ \\ ${ }^{1)}$ University of Utah Cancer Immunotherapy Program and ${ }^{2)}$ Department of Internal Medicine (Oncology and Infectious Disease) of the \\ University of Utah School of Medicine, Salt Lake City, UT 84132, U.S.A., ${ }^{3)}$ College of Veterinary Medicine, Kyungpook National \\ University, Daegu 702-701, ${ }^{4}$ Department of Internal Medicine (Hematology/Oncology) of the Chonbuk National University Medical \\ School, Chonju 561-712, 5) Department of Pharmacology, Wonkwang University School of Medicine, Iksan, Jeonbuk 570-749, Korea and \\ ${ }^{6)}$ Huntsman Cancer Institute, Suite 2100, 2000 Circle of Hope Dr., Salt Lake City, UT 84112-5550, U.S.A.
}

(Received 30 July 2003/Accepted 18 November 2003)

ABSTRACT. Nitric oxide (NO•) synthesis is induced within many tumors. The timecourse of NO• synthesis was evaluated during intraperitoneal Meth A fibrosarcoma progression. While increasing macrophage recruitment into ascites was noted, inducible nitric oxide synthase (iNOS) antigen and function peaked between days 3-6 after tumor implantation. The capacity of cells to respond to LPS and IFN $\gamma$ stimulation was markedly depressed on day 9 and 11. Cellular proliferation correlated in an inverse fashion with levels of NO• synthesis. Electron paramagnetic resonance spectroscopy and nitrotyrosine immunostaining failed to show accumulation of characteristic target cell lesions induced by NO• These findings lead us to conclude that NO• production was increasingly suppressed during Meth A tumor progression. Depression of NO• production did not correlate with levels of the inhibitory cytokines TGF $\beta$ and IL-10, but could be partially overcome by addition of sepiapterin (a tetrahydrobiopterin prodrug). Thus, depletion of essential co-factors necessary for iNOS function may contribute to depressed NO• responses during cancer progression.

KEY WORDS: fibrosarcoma, inducible nitric oxide synthase, macrophage, nitric oxide, tetrahydrobiopterin.

J. Vet. Med. Sci. 66(4): 357-365, 2004

Progressively growing cancers in animals and humans are variably infiltrated by host macrophages $[13,46,50]$. Conflicting data exists concerning the role of these tumor-infiltrating macrophages. In some studies, the degree of tumor infiltration by macrophages has correlated with a decrease in metastases or increased survival [13, 27, 32, 47, 50]. Other reports have suggested that macrophage infiltration of tumors may adversely affect host immune function and promote tumor growth [14, 15, 33, 35, 37].

Recent investigations have established that macrophages acquire potent antitumor and antimicrobial activity following exposure to the cytokines IFN $\gamma$ plus IL-1 and TNF (recently reviewed in $[19,38]$ ). Several groups of investigators proved that nitric oxide $(\mathrm{NO} \bullet)$ production was a major cytotoxic effector mechanism of such cytokine-activated macrophages [20, 34, 45]. The mechanisms for cytotoxic effects of NO• include inhibition of mitochondrial respiration and DNA replication via interaction with intracellular iron-sulfur [4Fe-4S] prosthetic groups of Complex I and Complex II of the mitochondrial electron transport system and the citric acid cycle enzyme aconitase, as well as nonheme iron in ribonucleotide reductase [11, 12, 16, 29, 48]. The cytokine inducible nitric oxide synthase (iNOS) gene has subsequently been cloned and sequenced [51].

Our previous experiments have demonstrated that NO• synthesis is activated in numerous murine tumors. This conclusion was reached based on measurement of NO• metabolites, iNOS expression and detection of iron-nitrosylation

\footnotetext{
* Correspondence to: Kwon, O.-D., College of Veterinary Medi-
} cine, Kyungpook National University, Daegu, 702-701, Korea. signals by electron paramagnetic resonance (EPR) spectroscopy $[4,53]$. Tumor cell proliferation was found to correlate inversely with $\mathrm{NO} \bullet$ synthesis [53]. Depletion experiments suggested that tumor-infiltrating macrophages played an important role in the intratumoral NO• synthesis [53]. Additional experiments demonstrated that endogenous $\mathrm{NO} \bullet$ synthesis could also be induced in tumor cells themselves by exposure to inflammatory cytokines [4]. Finally, mice treated with continuous infusions of the NOS inhibitor $\mathrm{N}^{\omega}$-monomethyl-L-arginine (MLA) demonstrated increased growth and delayed rejection of the highly antigenic ultraviolet radiation induced regressor tumor LR-298 [53]. An anti-metastatic effect of tumor-induced NO• production has subsequently been shown by Fidler and coworkers $[10,52]$. These experiments support the concept that macrophage-derived NO• synthesis could be beneficial to the host-antitumor immune response in vivo.

Other investigators have suggested that $\mathrm{NO} \bullet$ synthesis could influence host immune responses in a negative fashion. This conclusion is based on observations that NO• can act to decrease lymphocyte proliferation following antigen or mitogenic stimuli $[1,17,28,36,44]$. In some experiments, NO• appeared to inhibit antigen-specific cytotoxic $\mathrm{T}$ cell activation, particularly in alloantigen-directed responses [17, 21, 40, 44]. Tumor-associated NO• production has also been implicated in tumor neovascularization [22].

Since very little information exists concerning the kinetics of NO• synthesis during cancer growth, we performed experiments to characterize the timecourse of $\mathrm{NO} \bullet$ synthesis 
in a tumor that is known to be infiltrated by host macrophages. We predicted that if the predominant action of NO• were to facilitate tumor progression, NO• production should increase steadily during tumor growth. Progressive development of NO induced metabolic lesions in tumor cells, therefore, should also be detectable. In contrast, if the predominant action of $\mathrm{NO} \bullet$ were as an effector mechanism, one might predict that $\mathrm{NO} \bullet$ synthesis might decline during tumor progression. Intraperitoneal Meth A (a syngeneic tumor) was selected as a model, as it was known to grow aggressively in mice at subcutaneous or intraperitoneal sites of implantation. We have previously demonstrated intratumor NO• synthesis in subcutaneous Meth A tumors using EPR spectroscopy [4]. Furthermore, this tumor is known to be susceptible to $\mathrm{NO} \bullet$ induced growth inhibition and apoptosis $[41,54]$.

\section{MATERIALS AND METHODS}

Animals: Specific pathogen-free BALB/c mice (ages 6 to 8 weeks) were obtained from Harlan Sprague-Dawley (Indianapolis, IN) and housed in the University of Utah Animal Care Facility (Salt Lake City, Utah). Mice were maintained under guidelines established by the Institutional Animal Care and Use Committee, which also approved experimental protocols. Mice were age and sex matched at the onset of each experiment. All experiments were performed at least twice with highly concordant results.

Tumor cell lines: Meth A tumor (a gift from Dr. Lloyd Old, Memorial Sloan Kettering Cancer Center, New York, $\mathrm{NY}$ ) is a methylcholanthrene-induced spindle cell skin cancer arising in a BALB/c mouse. Tumor cell were maintained by serial i.p. passage in syngeneic BALB/c mice or by culture in RPMI 1640 medium supplemented with 5\% FCS (Hyclone Laboratories, Inc., Logan, UT), $100 \mathrm{U} / \mathrm{m} l$ penicillin G (Sigma Chemical Co., St. Louis, MO), $50 \mu \mathrm{g} /$ $\mathrm{m} l$ streptomycin (Sigma), and $2 \mathrm{mM}$ glutamine (Sigma)(working medium). In contrast to less virulent Meth A strains, the ascites variant of this tumor is extremely aggressive and is rapidly lethal to mice in 12 to 15 days following injection of $5 \times 10^{6}$ cells.

Mycoplasmal infection was excluded by periodic surveillance cultures of supernatants derived from the tumor cell line grown in antibiotic-free media on pleuropneumonialike organism agar (PPLO agar; Baxter Health Care Corporation, McGaw Park, IL) supplemented with $10 \%$ horse serum (Hyclone), 25\% yeast extract (Life Technologies, Inc., Gaithersburg, MD), and $10 \mathrm{U}$ penicillin $\mathrm{G} / \mathrm{ml}$.

Tumor model: At the beginning (day 0) of each experiment, normal BALB/c mice were injected i.p. with $5 \times 10^{6}$ Meth A tumor cells. On day 3, 6, 9, and 11 following tumor cell implantation, pairs of experimental mice were sacrificed. Ascites cells were isolated under sterile conditions, by extensively irrigating the peritoneal cavity with PBS. Cells were washed in working medium and erythrocytes were lysed by brief exposure to Tris-buffered $0.16 \mathrm{M}$ ammonium chloride. After further washes, cells were resus- pended to $10^{6}$ cells $/ \mathrm{m} l$ in working medium.

Cytologic evaluation of malignant ascites: Cells were diluted to $10^{6}$ cells $/ \mathrm{m} l$ and cytocentrifuge slides were prepared. Slides were stained with Wright's stain and a manual 200 cell differential count was performed on each slide. Results are expressed as absolute cell recovery per mouse (mean \pm SD) at each time point.

Immunofluorescent staining and flow cytometry: Ascites cells were suspended at $10^{6}$ cells $/ \mathrm{m} l$ in PBS containing 1 $\mathrm{mM} \mathrm{NaN}_{3}$ and $1 \%$ bovine albumin, and stained using previously described direct and indirect immunofluorescence techniques [42]. The macrophage content of ascites was determined by staining cells with FITC anti-CD11b (Mac-1; Boehringer Mannheim, Indianapolis, IN). Parallel cell samples were stained for iNOS enzyme expression following permeabilization by exposure to $70 \%$ ethanol, followed by incubation with $5 \mu \mathrm{g} / \mathrm{m} l$ rabbit anti-iNOS antiserum (Transduction Laboratories, Lexington, KY). Binding of this antiserum was detected using a FITC labeled goat-antirabbit immunoglobulin (Organon Teknika-Cappel, Durham, NC) at a predetermined optimal concentration. Following staining, cell samples were fixed in $1 \%$ paraformaldehyde, and $10^{4}$ cells analyzed on a FACScan flow cytometer (Becton Dickinson, Mountain View, CA) using a $25 \mathrm{~mW}$ argon laser with an emission wavelength of $488 \mathrm{~nm}$. Fluorescence histograms generated from $10^{4}$ unstained cells (direct immunofluorescence) or $10^{4}$ cells stained with secondary $\mathrm{Ab}$ alone (indirect immunofluorescence) served as negative controls. The use of pre-immune rabbit serum as a primary reagent served as an additional specificity control during indirect immunofluorescence staining.

Analysis of $\mathrm{NO} \cdot$ synthesis by ascites cells: Triplicate samples of cells $\left(2 \times 10^{5}\right.$ cells/ well $)$ were cultured in 96well flat-bottom microtiter plates in working medium. In some experiments, interferon- $\gamma$ (IFN $\gamma$, Genzyme, Cambridge, MA; $25 \mathrm{u} / \mathrm{ml}$ ), bacterial lipopolysaccharide (LPS, from Salmonella abortus equii, Sigma; $50 \mathrm{ng} / \mathrm{ml}$ ), sepiapterin (from B. Schirks, Jona, Switzerland; $60 \mu \mathrm{M}$ ) or $\mathrm{N}^{\omega_{-}}$ monomethyl-L-arginine (MLA, Cyclopss Biochemical Co., Salt Lake City, UT; $500 \mu \mathrm{M}$ ) was added at the onset of the culture. A constant final volume of $200 \mu \mathrm{l} /$ well was maintained in all experiments. After a $48 \mathrm{hr}$ incubation $\left(37^{\circ} \mathrm{C}\right.$ in a humidified $5 \% \mathrm{CO}_{2}$ incubator), accumulation of nitrite, a stable metabolite of $\mathrm{NO} \bullet$, was quantified in culture supernatants derived from triplicate wells, using a previously described colorimetric assay [53]. Sodium nitrite in working medium at concentrations ranging from 6.25 to $100 \mu \mathrm{M}$ served to establish a linear standard curve. Results are expressed as nitrite accumulation $/ 10^{5}$ cells (mean $\pm \mathrm{SD}$ ). Conversion of results to picomoles $/ 10^{5}$ cells can be obtained by multiplying experimental results by a factor of 50 . Working medium contained $<0.5 \mu \mathrm{M}$ nitrite.

Effect of $\mathrm{NO} \bullet$ on ascites cell proliferation: Microtiter wells containing $1.5 \times 10^{5}$ ascites cells in working medium were cultured in the presence or absence of MLA $(500 \mu \mathrm{M})$ for $30 \mathrm{hr}$ and then pulsed with tritiated thymidine $(0.5 \mu \mathrm{Ci} /$ well $\left[{ }^{3} \mathrm{H}\right]-\mathrm{TdR}, 2.0 \mathrm{Ci} / \mathrm{mmol}$; DuPont, Boston, MA) for an 
additional $18 \mathrm{hr}$ (total $48 \mathrm{hr}$ ), maintaining a constant final volume of $200 \mu \mathrm{l} / \mathrm{well}$. Following harvesting onto glass fiber filters using a PhD cell harvester (Cambridge Technology, Cambridge, MA), samples were suspended in Optifluor scintillation fluid (Packard, Downers Grove, IL) and the incorporated $\left[{ }^{3} \mathrm{H}\right]-\mathrm{TdR}$ was measured in a Packard Tricarb 1500 scintillation counter. Each assay was performed at least in triplicate and the results are expressed as CPM incorporation (mean $\pm \mathrm{SD}$ ).

Immunostaining of cytocentrifuge specimens: Cytocentrifuge specimens were fixed in acetone for $10 \mathrm{~min}$, and then incubated with anti-nitrotyrosine antiserum $(10 \mu \mathrm{g} / \mathrm{m} l)$ in sodium phosphate buffer ( $\mathrm{pH} 7.5$ ) for $30 \mathrm{~min}$. Binding of these primary antisera was detected, using a biotin-conjugated donkey-anti-rabbit antiserum (adsorbed for mouse reactivity; Jackson Immunoresearch Laboratories, West Grove, PA) and a Vectastain ABC-AP kit and Vector red alkaline-phosphatase substrate (Vector Laboratories, Burlingame, CA), following manufacturer's instructions. Levamisole ( $1 \mathrm{mM}$ ) was added to the color-development step to inhibit endogenous alkaline-phosphatase activity.

Electron paramagnetic resonance (EPR) spectroscopy: Centrifuged ascites cells (140 $\mu l$ packed cell volume/tube) were analyzed by EPR spectroscopy on a Bruker ESP-300E spectrometer operating at a microwave frequency of 9.65 $\mathrm{GHz}(5.0 \mathrm{~mW}$ power; modulation frequency, $100 \mathrm{kHz}$; and modulation amplitude, 1.0 millitesla). During data collection, the temperature was maintained at $77^{\circ} \mathrm{K}$ with an Oxford Instrument cryostat using liquid helium as coolant. The magnetic field was calibrated with reduced methylviologen. Instrument gains are stated in the figure legend (Fig. 4).

Analysis of inhibitory cytokine secretion by ascites cells: Production of cytokines thought to down regulate iNOS expression were analyzed by placing ascites cells into microtiter wells ( $10^{6}$ cells/well in $200 \mu l$ working medium). After $24 \mathrm{hr}$ in culture, cell culture supernatants $(100 \mu \mathrm{l})$ were assayed for IL-10 and total (free and latent) TGF $\beta$, using commercial kits obtained from R\&D systems (Minneapolis, MN) following manufacturers instructions.

\section{RESULTS}

A careful evaluation of the cellular composition of Meth A ascites was performed during tumor progression. Following extensive irrigation of the peritoneal cavity of experimental animals (4 mice per timepoint), cytocentrifuge slides were prepared from recovered cells derived from each mouse. A differential cell count was then performed. A rapid increase in tumor cells recovered from ascites from 3.5 $\times 10^{7}$ to $4.1 \times 10^{8}$ was observed from day 3 to day 9 . Macrophage and neutrophil accumulation in the malignant ascites also increased steadily over the course of the experiment (Fig. 1). The absolute number of macrophages contained in peritoneal washings rose gradually, from $1.2 \times 10^{6}$ cells $\left( \pm 0.9 \times 10^{6}\right)$ on day 3 , to $3.9 \times 10^{6}\left( \pm 1.9 \times 10^{6}\right)$ on day 6 , and $16.4 \times 10^{6}\left( \pm 6.5 \times 10^{6}\right)$ cells on day 9 . In contrast, the number of lymphocytes contained in the ascites appeared to plateau between day 6 and 9. By day 11-12 most animals were moribund due to tumor progression and were sacrificed.

Immunostaining of ascites cells was performed to further evaluate the host macrophage recruitment into the malignant ascites, as well as to evaluate induction of iNOS expression. This experiment demonstrated that the percentage of macrophages appeared to remain relatively constant (around 20\% Mac-1 stained cells in samples gated to include viable lymphocytes, macrophages and most tumor cells) (Fig. 2). Samples of ascites cells were also permeabilized and stained for iNOS expression. On day 3, about $17 \%$ of ascites cells were stained by iNOS antiserum. This fraction declined to $<3 \%$ by day 6 and remained at this low level on days 9 and 11 . Thus iNOS enzyme expression in malignant ascites was highest at early times during tumor progression, and subsequently declined.

Nitric oxide secretion by ascites cells was analyzed by measuring nitrite accumulation using a colorimetric assay. Cells obtained from mice on day 3, 6, 9 and 11 during progressive growth of intraperitoneal Meth A tumor were placed into microtiter wells and cultured for $24 \mathrm{hr}$ (Fig. 3A).

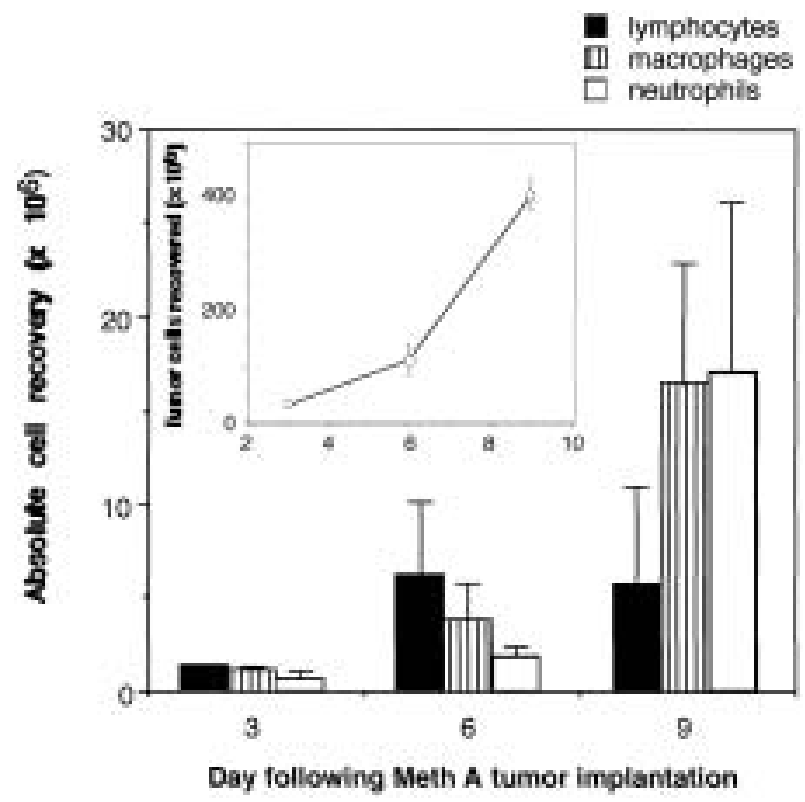

Fig. 1. Tumor cell and host leukocyte recovery during tumor progression. $\mathrm{BALB} / \mathrm{c}$ mice were injected i.p. with $5 \times 10^{6}$ Meth A tumor cells. On day 3, 6, 9, and 11 following tumor cell implantation, pairs of experimental mice were sacrificed. Ascites cells were isolated from each animal under sterile conditions by extensively irrigating the peritoneal cavity with PBS. Cells were washed in working medium and erythrocytes were lysed by brief exposure to Tris-buffered $0.16 \mathrm{M}$ ammonium chloride. Cells were diluted to $10^{6}$ cells $/ \mathrm{m} l$ and cytocentrifuge slides were prepared and stained with Wright's stain. A manual 200 cell differential count was performed on each slide. Results are expressed as absolute cell recovery per mouse (mean $\pm \mathrm{SD}$ ) at each time point. 


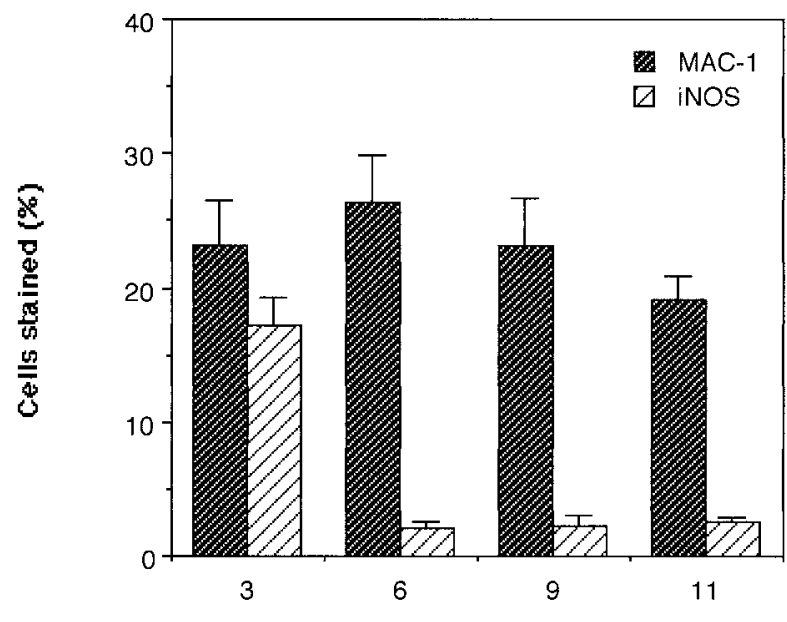

Day following Meth A tumor implantation

Fig. 2. Identification of MAC-1 and iNOS expressing cells during tumor growth. Ascites cells were suspended at $10^{6} \mathrm{cell} / \mathrm{ml}$ in PBS containing $1 \mathrm{mM} \mathrm{NaN}$ and $1 \%$ bovine albumin, and stained with FITC anti-CD11b. Parallel cell samples were permeabilized with methanol and exposed to a rabbit anti-iNOS antiserum. Binding was detected, using FITC labeled goat-antirabbit immunoglobulin. Cell samples were fixed in $1 \%$ paraformaldehyde, and $10^{4}$ cells analyzed on a FACScan flow cytometer Fluorescence histograms generated from $10^{4}$ unstained cells (direct immunofluorescence) or $10^{4}$ cells stained with secondary $\mathrm{Ab}$ alone (indirect immunofluorescence) served as negative controls.

A low level of nitrite synthesis $(0.9 \pm 0.1 \mu \mathrm{M})$ was observed in samples derived from mice on day 3 following tumor implantation, which increased to $4.1 \pm 1.6 \mu \mathrm{M}$ by day 6 . In contrast, an equivalent number of ascites cells from mice on day 9 and 11 synthesized minimal nitrite $(<0.6 \mu \mathrm{M})$. This result suggested that $\mathrm{NO} \cdot$ was produced in small amounts during the early immune response to intraperitoneal Meth A tumor cells, but that production was depressed as the tumor progressed. Addition of monomethyl-L-arginine (MLA), resulted in a decrease in nitrite accumulation, confirming that the L-arginine: $\mathrm{NO} \bullet$ pathway was the source of nitrite production.

The capacity of ascites cells to synthesize $\mathrm{NO} \bullet$ in response to a strong pro-inflammatory stimulus was also tested. LPS $(50 n \mathrm{~g} / \mathrm{m} l)$ and $\operatorname{IFN}(25 \mathrm{u} / \mathrm{ml} l)$ were added to ascites cells in microtiter wells in the presence or absence of MLA $(500 \mu \mathrm{M})$. Nitrite production in ascites cells derived from the day 3 and 6 experimental groups was markedly increased by LPS/IFN $\gamma$ exposure (to $12.3 \pm 2.7$ and $16.7 \pm$ $1.4 \mu \mathrm{M}$, respectively). This increase was inhibited by MLA. Unexpectedly, the capacity of ascites cells to synthesize $\mathrm{NO} \cdot$ in response to LPS/INF $\gamma$ was found to be markedly depressed in day 9 and 11 samples.

At the same timepoints, parallel samples of ascites cells were pulsed with $\left[{ }^{3} \mathrm{H}\right]-\mathrm{TdR}$ to assess cellular proliferation. Untreated ascites cells demonstrated high levels of thymi- dine incorporation at all experimental timepoints, which was not inhibited by addition of MLA (Fig. 3B). Induction of NO• synthesis in malignant ascites via addition of LPS/ IFN $\gamma$ resulted in a significant decrease in $\left[{ }^{3} \mathrm{H}\right]-\mathrm{TdR}$ incorporation into DNA. The antiproliferative effect of LPS/IFN $\gamma$ appeared to be lost by day 9 and 11, in parallel to observed depressions in $\mathrm{NO} \bullet$ synthesis in response to these inflammatory mediators.

Ascites cells were evaluated by electron paramagnetic resonance (EPR) spectroscopy for evidence of accumulation of $\mathrm{NO} \bullet$ induced cellular injury from low-level NO• production (Fig. 4). This experiment demonstrated that most samples of intraperitoneal Meth A tumor did not exhibit any iron nitrosylation signals on day 3 (Tracing A) or day 6 (Tracing B) (3/3 samples each). On day 9 and 11 (Tracing C) a large semiquinone signal at $\mathrm{G}=2.003$ was seen. In 1 of 3 samples on day 9 (Tracing D) and 1 of 3 samples on day 11 (not shown), which were noted to be grossly hemorrhagic, a small nitrosyl heme signal (a triplet peak centered at $g=2.012$ ), superimposed on the semiquinone trough was seen. Dithio-iron nitrosylation signals (thought to relate to interaction of $\mathrm{NO} \cdot$ with $[4 \mathrm{Fe}-4 \mathrm{~S}]$ prosthetic groups of enzymes involved in mitochondrial respiration) were not observed in any sample. In contrast, exposure of Meth A tumor cells derived from long term cell cultures to the NO• donor S-nitroso-penicillamine $(100 \mu \mathrm{M})$ induced a strong nitrosyl heme signal, as well as a small dithio-dinitro iron signal ( $\mathrm{g}=2.039)$ (Tracing $\mathrm{E})$.

Cell samples obtained at the same timepoints were also stained by immunohistochemical techniques for nitrotyrosine formation (a product of the reaction of peroxynitrite with cellular proteins) by alkaline phosphatase immunostaining. Nitrotyrosine formation was not detected in any ascites sample, while cytokine-activated murine macrophages showed auto-reactivity (data not shown).

To further investigate possible mechanisms that might account for low levels of baseline NO• production, and the depressed response of ascites cells to LPS/IFN $\gamma$ stimulation on days 9 and 11, we questioned whether increasing levels of inhibitory cytokines were produced during tumor progression. Previous investigators have established that TGF $\beta$ and IL-10 are capable of inhibiting macrophage NO• synthesis $[9,31]$. This experiment (Table 1) demonstrated that low levels $(\sim 25-30 \mathrm{pg} / \mathrm{m} l)$ of IL-10 were detectable at all time points. These levels remained constant and did not correlate with progressive inhibition of $\mathrm{NO} \bullet$ synthesis. Neither free or latent TGF $\beta$ was detectable (at the $<2 \mathrm{pg} / \mathrm{m} l$ level) in culture supernatants at any timepoint. Thus, the suppression of NO• production did not appear to be correlate with levels of inhibitory cytokine.

We performed a further experiment to evaluate whether tetrahydrobiopterin, a co-factor required for the function of the iNOS enzyme [24], was depleted during rapid progression of ascites tumor. This experiment (Fig. 5) demonstrated that baseline nitrite accumulation in cultured ascites cells was only minimally altered by addition of $60 \mu \mathrm{M}$ sepiapterin, a substrate for the pterin salvage pathway of tetrahy- 


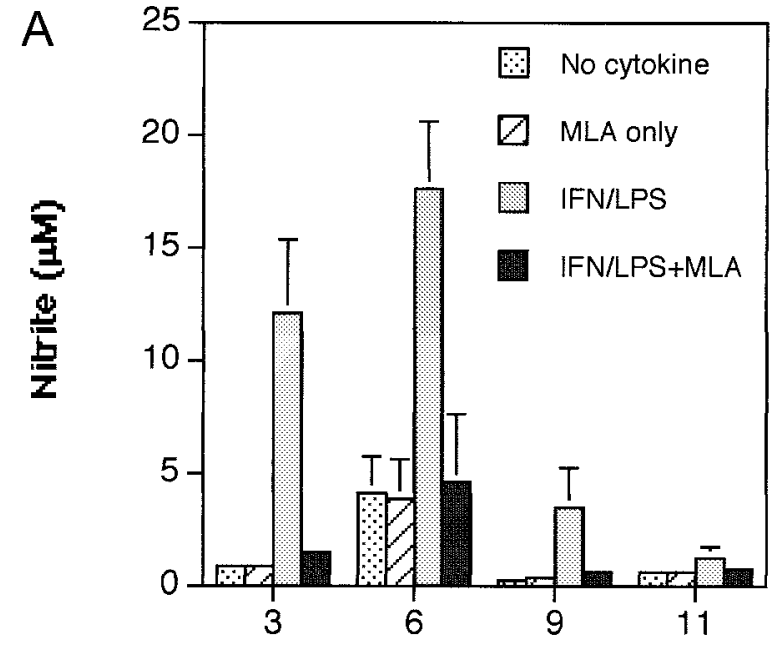

Day following Meth A tumor implantation

Fig. 3A. Evaluation of the capacity of ascites cells to produce NO•. Triplicate samples of ascites cells were cultured in working medium $\left(2 \times 10^{5}\right.$ cells/ microtiter well $)$. After a $48 \mathrm{hr}$ incubation $\left(37^{\circ} \mathrm{C}\right.$ in a humidified $5 \% \mathrm{CO}_{2}$ incubator), accumulation of nitrite, a stable metabolite of $\mathrm{NO}$, was quantified in culture supernatants derived from triplicate wells, using a colorimetric assay. $\mathrm{N}^{\mathrm{G}}$-monomethyl-L-arginine (MLA, $500 \mu \mathrm{M}$ ) was added to replicate wells to confirm origin of nitrite from the L-arginine: NO• pathway. Sodium nitrite in working medium at concentrations ranging from 6.25 to $100 \mu \mathrm{M}$ served to establish a linear standard. Results are expressed as nitrite accumulation/ $10^{5}$ cells (mean $\pm \mathrm{SD}$ ). The ability of cells to respond to interferon- $\gamma(25 \mathrm{u} / \mathrm{m} l)$ and LPS $(50 \mathrm{ng} / \mathrm{m} l)$ was also tested. A constant final volume of $200 \mu \mathrm{l} /$ well was maintained in all wells.

drobiopterin synthesis. Responses to LPS/IFN $\gamma$ stimulation of ascites cells demonstrated that addition of sepiapterin markedly increased nitrite secretion into cell cultures. Sepiapterin addition was able to partially correct the hyporesponsiveness of day 9 and day 11 ascites cells for induction of NO•. synthesis in response to LPS/IFN $\gamma$, suggesting that depletion of essential cofactors needed for macrophage cytotoxicity may contribute to progressive macrophage hyporesponsiveness during tumor progression.

\section{DISCUSSION}

The function of NO- synthesis in the tumor microenvironment remains uncertain. $\mathrm{NO} \bullet$ is known to inhibit tumor cell energy metabolism via inactivation of Complex I and Complex II of the mitochondrial electron transport system and the citric acid cycle enzyme aconitase [11, 12, 16, 48]. Cellular proliferation is depressed in target cells, due to inhibition of ribonucleotide reductase, the rate limiting enzyme in DNA synthesis $[25,29]$. The net effect is cytostasis of tumor target cells. More recently, studies have shown that exposure of tumor cells to NO• also can induce programmed cell death as a potential cytolytic mechanism $[8,41]$.

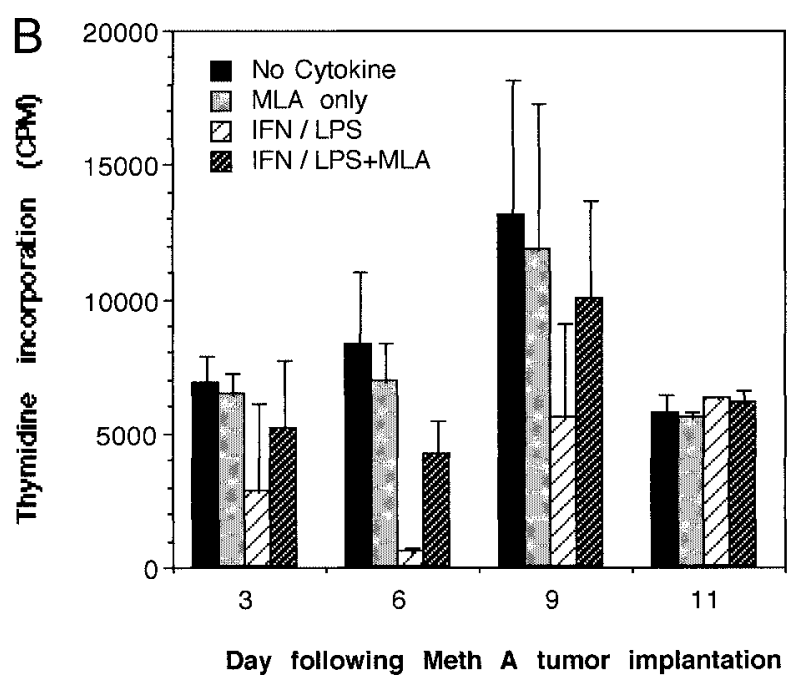

Fig. 3B. Effect of ascites cell NO• synthesis on proliferation. Triplicate microtiter wells containing $1.5 \times 10^{5}$ ascites cells in working medium were cultured in the presence or absence of MLA (500 $\mu \mathrm{M})$ for $30 \mathrm{hr}$ and then pulsed with tritiated thymidine $(0.5 \mu \mathrm{Ci} /$ well $\left[{ }^{3} \mathrm{H}\right]-\mathrm{TdR}, 2.0 \mathrm{Ci} / \mathrm{mmol}$; DuPont, Boston, MA) for an additional $18 \mathrm{hr}$ (total $48 \mathrm{hr}$ ). Additional samples were exposed to LPS and IFN $\gamma$, to measure the responsiveness of cells to strong agonist signals. A constant final volume of $200 \mu \mathrm{l} / \mathrm{well}$ was maintained. Following harvesting onto glass fiber filters using a $\mathrm{PhD}$ cell harvester (Cambridge Technology, Cambridge, MA), samples were suspended in Optifluor scintillation fluid (Packard, Downers Grove, IL) and the incorporated $\left[{ }^{3} \mathrm{H}\right]-\mathrm{TdR}$ was measured in a Packard Tricarb 1500 scintillation counter (Packard). The results are expressed as mean $\mathrm{CPM} \pm \mathrm{SD}$.

Analysis of the timing of $\mathrm{NO}$ production in the tumor microenvironment may provide useful clues as to the role(s) of this radical during tumor growth. Our studies of syngeneic Meth A tumor in the peritoneal cavity of mice demonstrated a progressive accumulation of macrophages in malignant Meth A ascites during tumor growth. Surprisingly, expression of the iNOS enzyme appeared to peak early following tumor implantation (day 3), and subsequently declined. Quantitation of nitrite synthesis, an NO• metabolite, by ascites cells established that peak NO• secretion occurred between days 3-6 and then decreased, despite the progressive expansion in tumor cell and macrophage numbers in the malignant ascites. Mills et al. also noted low levels of nitrite accumulation and citrulline synthesis (a product of the L-arginine: $\mathrm{NO} \bullet$ pathway) during the progressive intraperitoneal growth of P815 mastocytoma in C57Bl/ $6 \times \mathrm{DBA} / 2$ F1 mice [37]. These investigators showed that markedly increased levels of both metabolites were induced when P815 cells from immunized mice were analyzed. This finding correlated with subsequent rejection of the implanted tumor. NO• synthesis in immune mice was suspected to be induced by lymphocyte-derived cytokines. Indeed, increased IFN $\gamma$ mRNA and protein synthesis was detected in ascites cells from immunized versus control 

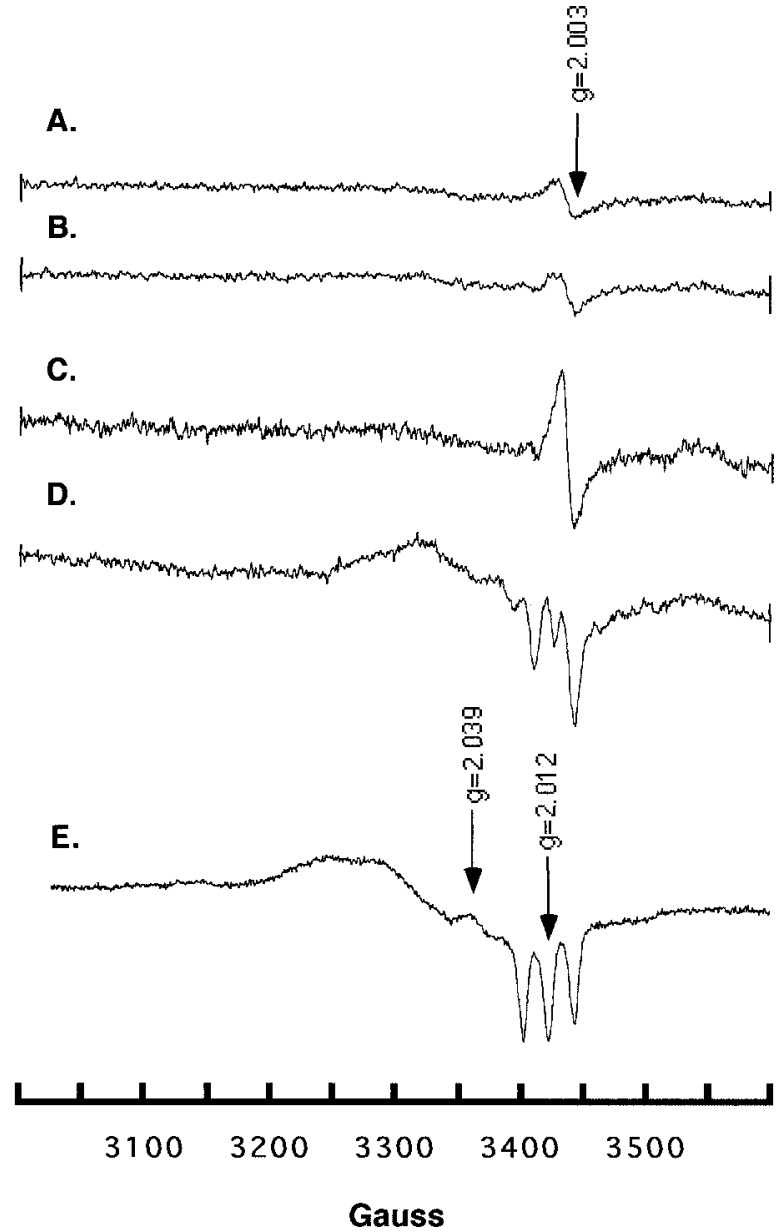

Fig. 4. Electron paramagnetic resonance (EPR) spectroscopy during tumor progression. Centrifuged ascites cells (140 $\mu l$ packed cell volume/tube) were analyzed by EPR spectroscopy. Tracing A) Day 3-no NO signal, B) Day 6-no NO signal, C) Day 9-no NO signal, D) Day 9 (1 of 3 mice showed heme nitrosylation signal), E) Meth A cells incubated with NO donor SNAP in vitro with induction of strong heme nitrosylation $(\mathrm{g}=2.012)$ and weak dithio-dinitro signal $(\mathrm{g}=2.039)$ indicated by arrows. Instrument gain was constant $\left(1.25 \times 10^{5}\right)$ in each tracing.

mice [37].

We evaluated whether chronic low levels of NO• synthesis resulted in characteristic dithio-dinitro iron EPR signals, which are thought to represent the metabolic lesions induced by $\mathrm{NO} \cdot$ in iron-sulfur [4Fe-4S] prosthetic groups of aconitase and Complex 1 and 2 of the electron transport chain [26]. These EPR signals were not detectable in Meth A ascites specimens at any time. Nitrosyl-heme signals were detected in occasional ascites specimens that appeared grossly contaminated with erythrocytes. These signals could be the result of the interaction of small amounts of NO• with hemoglobin in erythrocytes. Alternatively, nitrosyl-heme signals appear to be induced in some tumors, including Meth A, following endogenous NO• exposure [4].

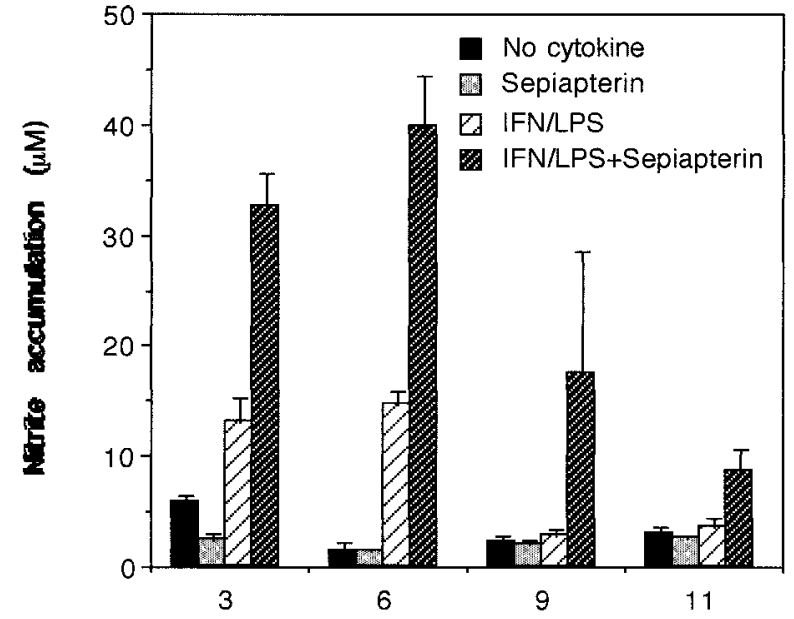

Day following Meth A tumor implantation

Fig. 5.Effect of sepiapterin addition on NO synthesis by ascites cells. Triplicate samples of cells $\left(2 \times 10^{5}\right.$ cells/well $)$ were cultured in 96-well flat-bottom microtiter plates with or without addition of sepiapterin $(60 \mu \mathrm{M})$. In some samples, interferon- $\gamma(25$ $\mathrm{u} / \mathrm{m} l)$ and LPS $(50 n \mathrm{~g} / \mathrm{m} l)$ to further induce iNOS function. A constant final volume of $200 \mu \mathrm{l} / \mathrm{well}$ was maintained in all experiments. After a $48 \mathrm{hr}$ incubation $\left(37^{\circ} \mathrm{C}\right.$ in a humidified $5 \% \mathrm{CO}_{2}$ incubator), accumulation of nitrite, a stable metabolite of $\mathrm{NO}$, was quantified. Results are expressed as nitrite accumulation $/ 10^{5}$ cells (mean $\pm \mathrm{SD}$ ).

Table 1. Secretion of potentially inhibitory cytokines by Meth A ascites cells during tumor progression

\begin{tabular}{cccc}
\hline & Day 3 & Day 6 & Day 9 \\
\hline IL-10 & $25.7 \pm 2.2 \mathrm{pg} / \mathrm{m} l$ & $25.9 \pm 3.4 \mathrm{pg} / \mathrm{m} l$ & $28.7 \pm 5.7 \mathrm{pg} / \mathrm{m} l$ \\
TGF $\beta$ & $<2 \mathrm{pg} / \mathrm{m} l$ & $<2 \mathrm{pg} / \mathrm{m} l$ & $<2 \mathrm{pg} / \mathrm{m} l$ \\
\hline
\end{tabular}

Meth A tumor cells were obtained during tumor progression, at the times shown. Cytokine secretion of ascites cells was analyzed by placing ascites cells into triplicate microtiter wells $\left(10^{6}\right.$ cells/well in $200 \mu l$ complete medium). After $24 \mathrm{hr}$ in culture, $100 \mu \mathrm{l}$ cell culture supernatants were assayed for IL-10 and total (free and latent) TGF $\beta$ using commercial immunoassay kits.

The significance of these nitrosyl-heme signals are currently under investigation. Substantial evidence for increased oxidative free radical production during tumor growth was seen, indicated by an increasing semiquinone trough at $\mathrm{g}=2.003$.

Peroxynitrite has been proposed as a major mediator of NO• induced cellular injury $[5,30]$. This reactive species, which is formed by the interaction of $\mathrm{NO} \cdot$ with superoxide [23], is capable of inducing oxidative damage to cellular proteins and lipids $[39,40]$. Due to the increased evidence for oxidative radical formation by EPR spectroscopy, we evaluated whether nitrotyrosine, a reaction product of the interaction of peroxynitrite with cellular proteins [40], could be detected in Meth A ascites. Immunohistochemical staining was unable to identify expression of nitrotyrosine in 
ascites tumor cells or macrophages at any time during tumor progression. In contrast, staining of LPS/IFN $\gamma$ activated macrophages showed readily identifiable expression of nitrotyrosine. These findings indicated that cellular injury by $\mathrm{NO} \cdot$ reaction products was not accumulating during Meth A tumor progression.

There are several conclusions that can be reached from these findings. First, NO• production did not correlate with tumor progression in this tumor model, since evidence for production was only detectable early following tumor implantation and subsequently declined. Addition of proinflammatory mediators (LPS/IFN $\gamma$ ) resulted in NO• synthesis and antiproliferative effects in Meth A ascites. A novel finding in the current experiments was the observation that ascites cells become hyporesponsive to LPS/IFN $\gamma$ during tumor progression. This depression in NO• synthesis occurred despite increasing intraperitoneal macrophage accumulation. Several possibilities could account for this apparent tumor-associated suppression of NO• synthesis. Studies by other investigators have demonstrated that the IL-10 and TGF $\beta$ can inhibit macrophage NO• synthesis [6, 7]. In one case, a methylcholanthrene-induced fibrosarcoma was shown to produce these inhibitory cytokines [3]. We evaluated whether these cytokines were secreted into Meth A ascites. TGF $\beta$ was not detectable by immunoassay at any timepoint. Only low levels of IL-10 were found, which remained stable throughout the course of the experiment. Thus progressive inhibition of $\mathrm{NO}$ - production did not appear to correlate with observed levels of potentially inhibitory cytokines. Whether other cytokines or prostaglandins could contribute to macrophage hyporesponsiveness will require further investigation.

Another possibility we considered, was that depletion of cofactors necessary for iNOS function might occur during progressive tumor growth. In particular, we hypothesized that tetrahydrobiopterin, an important cofactor for iNOS function [18], could become depleted. To test this possibility, ascites cells were cultured with sepiapterin, a substrate for the pteridine salvage pathway. This experiment demonstrated that baseline NO• synthesis was not significantly affected by addition of sepiapterin. In contrast, LPS/IFN $\gamma$ stimulated responses were markedly increased at all time points, suggesting that tetrahydrobiopterin was rate limiting for NO• production by ascites cells. Furthermore, addition of sepiapterin was able to partially overcome the suppression of cytokine-inducible NO• synthesis observed on days 9 and 11, suggesting that depletion of cofactors and metabolic substrates could be responsible for much of the observed hyporesponsiveness of ascites cells.

It is important to emphasize that the role of $\mathrm{NO} \cdot$ as a hostdefense against tumors is currently controversial. Our previous studies support a predominantly antiproliferative role for NO• in murine tumor models $[53,54]$. Experiments in which tumor cells have been transfected with iNOS genes have demonstrated decreased tumor growth [22] and metastasis [52] in normal mice compared to parental cells. Furthermore, Albina and colleagues have shown that NO• can induce programmed cell death in macrophages and other targets [2,8]. We recently established that Meth A tumor cells are induced to undergo apoptosis following NO• exposure, raising the possibility that $\mathrm{NO} \bullet$ may function as cytolytic, rather than cytostatic antitumor mechanism in vivo. The conditions under which $\mathrm{NO} \cdot$ can mediate programmed cell death in tumor target cells is undergoing further evaluation.

It should be noted that $\mathrm{NO} \bullet$ could also have negative effects on host immune responses to tumor. $\mathrm{NO} \bullet$ and its congeners may mediate oxidative tissue damage [39, 43, 49]. In immunocompromised mice, iNOS transfected tumor cells appeared to grow at an accelerated rate and tumor neovascularity was notably increased [22]. NO• appears to have immunosuppressive potential, resulting in decreased proliferation of mitogen activated lymphocytes $[1,17,36$, 44]. In high concentrations, $\mathrm{NO} \cdot$ also appears to have the capacity to inhibit antigen-specific cytotoxic $\mathrm{T}$ cell activation $[17,21,40,44]$. Our own studies suggest that the cytotoxicity of pre-activated cytolytic effector cells remains intact following $\mathrm{NO} \bullet$ exposure (manuscript in preparation). Thus, the theoretical possibility exists that NO• could contribute to tumor progression [28].

To unify these conflicting observations, we have proposed that high local concentrations of $\mathrm{NO} \bullet$ in the tumor microenvironment may be beneficial during the induction of anticancer immune responses, by inhibiting tumor cell proliferation and cellular respiration. But the interrelationship of the antitumor and immunosuppressive roles of $\mathrm{NO} \bullet$ is likely to be complex. Further work will clearly be necessary to define the conditions under which $\mathrm{NO} \bullet$ is useful to the host immune response against tumors. Such studies may aid in the development of effective pharmacologic delivery techniques to optimize tumor cell killing by NO•.

ACKNOWLEDGMENTS. This work was supported by grants U01-CA58248 and R01-CA67404 from the National Cancer Institute, National Institutes of Health. The University of Utah Cancer Center Core Flow Cytometry Facility is supported by Clinical Cancer Center Core Grant CA 42014 from the National Institutes of Health.

\section{REFERENCES}

1. Albina, J.E., Abate, J.A. and Henry, W.L. Jr. 1991. Nitric oxide production is required for murine resident peritoneal macrophages to suppress mitogen-stimulated $\mathrm{T}$ cell proliferation. Role of IFN-gamma in the induction of the nitric oxide-synthesizing pathway. J. Immunol. 147: 144-148.

2. Albina, J.E., Cui, S., Mateo, R.B. and Reichner, J.S. 1993. Nitric oxide-mediated apoptosis in murine peritoneal macrophages. J. Immunol. 150: 5080-5085.

3. Alleva, D.G., Burger, C.J. and Elgert, K.D. 1994. Tumorinduced regulation of suppressor macrophage nitric oxide and TNF-alpha production. Role of tumor-derived IL-10, TGFbeta, and prostaglandin E2. J. Immunol. 153: 1674-1686.

4. Bastian, N.R., Yim, C.-Y., Hibbs, J.B. Jr. and Samlowski, W.E. 1994. Induction of iron-derived EPR signals in murine cancers by nitric oxide: Evidence for multiple intracellular tar- 
gets. J. Biol. Chem. 269: 5127-5131.

5. Beckman, J.S. 1994. Peroxynitrite versus hydroxyl radical: the role of nitric oxide in superoxide-dependent cerebral injury. Ann. New York Acad. Sci. 738: 69-75.

6. Bogdan, C., Paik, J., Vodovotz, Y. and Nathan, C. 1992. Contrasting mechanisms for suppression of macrophage cytokine release by transforming growth factor-beta and interleukin-10. J. Biol. Chem. 267: 23301-23308.

7. Bogdan, C., Vodovotz, Y. and Nathan, C. 1991. Macrophage deactivation by interleukin 10. J. Exp. Med. 174: 1549-1555.

8. Cui, S., Reichner, J.S., Mateo, R.B. and Albina, J.E. 1994. Activated murine macrophages induce apoptosis in tumor cells through nitric oxide-dependent or -independent mechanisms. Cancer Res. 54: 2462-2467.

9. Ding, A., Nathan, C.F., Graycar, J., Derynck, R., Stuehr, D.J. and Srimal, S. 1990. Macrophage deactivating factor and transforming growth factors- $\beta 1,-\beta 2$, and $-\beta 3$ inhibit induction of macrophage nitric oxide synthesis by IFN $\gamma$. J. Immunol. 145: 940-944.

10. Dong, Z., Staroselsky, A.H., Qi, X., Xie, K. and Fidler, I.J. 1994. Inverse correlation between expression of inducible nitric oxide synthase activity and production of metastases in K-1735 murine melanoma cells. Cancer Res. 54: 789-793.

11. Drapier, J.-C. and Hibbs, J.B. Jr. 1986. Murine cytotoxic activated macrophages inhibit aconitase in tumor cells. Inhibition involves the iron-sulfur prosthetic group and is reversible. $J$. Clin. Invest. 78: 790-797.

12. Drapier, J.-C. and Hibbs, J.B. Jr. 1988. Differentiation of murine macrophages to express nonspecific cytotoxicity for tumor cells results in L-arginine-dependent inhibition of mitochondrial iron-sulfur enzymes in the macrophage effector cells. J. Immunol. 140: 2829-2838.

13. Eccles, S.A. and Alexander, P. 1974. Macrophage content of tumours in relation to metastatic spread and host immune reaction. Nature (Lond.) 250: 667-669.

14. Eccles, S.A. and Alexander, P. 1974. Sequestration of macrophages in growing tumors and its effect on the immunologic capacity of the host. Br. J. Cancer 30: 42-49.

15. Gillespie, G.Y. and Russell, S.W. 1980. Level of activation determines whether inflammatory peritoneal and intratumoral macrophages will promote or suppress in vitro development of cytolytic T lymphocyte activity. J. Reticuloendothel. Soc. 27: 535-545.

16. Granger, D.L. and Lehninger, A.L. 1982. Sites of inhibition of mitochondrial electron transport in macrophage-injured neoplastic cells. J. Cell Biol. 95: 527-535.

17. Gregory, S.H., Wing, E.J., Hoffman, R.A. and Simmons, R.L. 1993. Reactive nitrogen intermediates suppress the primary immunologic response to Listeria. J. Immunol. 150: 29012909.

18. Gross, S.S., Jaffe, E.A., Levi, R. and Kilbourn, R.G. 1991. Cytokine-activated endothelial cells express an isotype of nitric oxide synthase which is tetrahydrobiopterin-dependent, calmodulin-independent and inhibited by arginine analogs with a rank-order of potency characteristic of activated macrophages. Biochem. Biophys. Res. Commun. 178: 823-829.

19. Hibbs, J.B. Jr., Taintor, R.R., Vavrin, Z., Granger, D.L., Drapier, J.-C., Amber, I.J. and Lancaster, J.R. Jr. 1990. Synthesis of nitric oxide from a terminal guanidino nitrogen atom of L-arginine: A molecular mechanism for regulating cellular proliferation that targets intracellular iron. pp. 189-223. In: Nitric Oxide from L-Arginine: A Bioregulatory System (Moncada, S. and Higgs, E.A. eds), Elsevier Science Publishers B.V., New
York.

20. Hibbs, J.B. Jr., Taintor, R.R., Vavrin, Z. and Rachlin, E.M. 1988. Nitric oxide: a cytotoxic activated macrophage effector molecule. Biochem. Biophys. Res. Commun. 157: 87-94.

21. Hoffman, R.A., Langrehr, J.M., Wren, S.M., Dull, K.E., Ildstad, S.T., McCarthy, S.A. and Simmons, R.L. 1993. Characterization of the immunosuppressive effects of nitric oxide in graft vs host disease. J. Immunol. 151: 1508-1518.

22. Jenkins, D.C., Charles, I.G., Thomsen, L.L., Moss, D.W., Holmes, L.S., Baylis, S.A., Rhodes, P., Westmore, K., Emson, P.C. and Moncada, S. 1995. Roles of nitric oxide in tumor growth. Proc. Natl. Acad. Sci. U.S.A. 92: 4292-4296.

23. Koppenol, W.H., Moreno, J.J., Pryor, W.A., Ischiropoulos, H. and Beckman, J.S. 1992. Peroxynitrite, a cloaked oxidant formed by nitric oxide and superoxide. Chem. Res. Toxicol. 5: 834-842.

24. Kwon, N.S., Nathan, C.F. and Stuehr, D.J. 1989. Reduced biopterin as a cofactor in the generation of nitrogen oxides by murine macrophages. J. Biol. Chem. 264: 20496-20501.

25. Kwon, N.S., Stuehr, D.J. and Nathan, C.F. 1991. Inhibition of tumor cell ribonucleotide reductase by macrophage-derived nitric oxide. J. Exp. Med. 174: 761-767.

26. Lancaster, J.R. Jr. and Hibbs, J.B. Jr. 1990. EPR demonstration of iron-nitrosyl complex formation by cytotoxic activated macrophages. Proc. Natl. Acad. Sci. U.S.A. 87: 1223-1227.

27. Lauder, I., Aherne, W., Stewart, J. and Sainsbury, R. 1977. Macrophage infiltration of breast tumors: A prospective study. J. Clin. Pathol. 30: 563-568.

28. Lejeune, P., Lagadec, P., Onier, N., Pinard, D., Ohshima, H. and Jeannin, J.F. 1994. Nitric oxide involvement in tumorinduced immunosuppression. J. Immunol. 152: 5077-5083.

29. Lepoivre, M., Fieschi, F., Coves, J., Thelander, L. and Fontecave, M. 1991. Inactivation of ribonucleotide reductase by nitric oxide. Biochem. Biophys. Res. Commun. 179: 442-448.

30. Lipton, S.A., Choi, Y.-B., Pan, Z.-H., Lei, S.Z., Chen, H.-S.V., Sucher, N.J., Loscalzo, J., Singel, D.J. and Stamler, J.S. 1993. A redox-based mechanism for the neuroprotective and neurodestructive effects of nitric oxide and related nitroso-compounds. Nature (Lond.) 364: 626-632.

31. Lue, K.H., Lauener, R.P., Winchester, R.J., Geha, R.S. and Vercelli, D. 1991. Engagement of CD14 on human monocytes terminates $\mathrm{T}$ cell proliferation by delivering a negative signal to T cells. J. Immunol. 147: 1134-1138.

32. Mahoney, K.H. and Heppner, G.H. 1987. FACS analysis of tumor-associated macrophage replication: Differences between metastatic and non-metastatic murine mammary tumors. $J$. Leukocyte. Biol. 41: 205-211.

33. Mantovani, A., Bottazzi, B., Colotta, F., Sozzani, S. and Ruco, L. 1992. The origin and function of tumor-associated macrophages. Immunol. Today 13: 265-270.

34. Marletta, M.A., Yoon, P.S., Iyengar, R., Leaf, C.D. and Wishnock, J.S. 1988. Macrophage oxidation of L-arginine to nitrite and nitrate: Nitric oxide is an intermediate. Biochemisty 27: 8706-8711.

35. McBride, W.H. 1986. Phenotype and functions of intratumoral macrophages. Biochem. Biophys. Acta 865: 27-41.

36. Mills, C.D. 1991. Molecular basis of "suppressor" macrophages. Arginine metabolism via the nitric oxide synthetase pathway. J. Immunol. 146: 2719-2723.

37. Mills, C.D., Shearer, J., Evans, R. and Caldwell, M.D. 1992. Macrophage arginine metabolism and the inhibition or stimulation of cancer. J. Immunol. 149: 2709-2714.

38. Nathan, C. 1992. Nitric oxide as a secretory product of mam- 
malian cells. FASEB J. 6: 3051-3064.

39. Radi, R., Beckman, J.S., Bush, K.M. and Freeman, B.A. 1991. Peroxynitrite-induced membrane lipid peroxidation: The cytotoxic potential of superoxide and nitric oxide. Arch. Biochem. Biophys. 288: 481-487.

40. Radi, R., Beckman, J.S., Bush, K.M. and Freeman, B.A. 1991. Peroxynitrite oxidation of sulfhydryls: The cytotoxic potential of superoxide and nitric oxide. J. Biol. Chem. 266: 4244-4250.

41. Samlowski, W.E., McGregor, J.R., Bastian, N.R., Kwon, O.-D. and Yim, C.-Y. 1996. Tumor cell apoptosis may represent a novel cytotoxic mechanism resulting from IL-2 induced nitric oxide (NO•) synthesis. p. 164. In: The Biology of Nitric Oxide (Stamler, J.S., Gross, S.S. and Moncada, S. eds), Portland Press, London.

42. Samlowski, W.E., McGregor, J.R. and Litton, G.J. 1989. Liver sequestration of murine lymphokine-activated killer (LAK) cells is mediated by carbohydrate-specific receptors. Reg. Immunol. 2: 254-265.

43. Stamler, J.S., Singel, D.J. and Loscalzo, J. 1992. Biochemistry of nitric oxide and its redox-activated forms. Science $\mathbf{2 5 8}$ : 1898-1902.

44. Stefani, M.M., Muller, I. and Louis, J.A. 1994. Leishmania major-specific CD8+ T cells are inducers and targets of nitric oxide produced by parasitized macrophages. Eur. J. Immunol. 24: 746-752.

45. Stuehr, D.J. and Nathan, C.F. 1989. Nitric oxide: A macrophage product responsible for cytostasis and respiratory inhibition in tumor target cells. J. Exp. Med. 169: 1543-1555.

46. Svennevig, J.-L., Loevik, M. and Svaar, H. 1979. Isolation and characterization of lymphocytes and macrophages from solid, malignant human tumors. Int. J. Cancer 23: 626-631.

47. Underwood, J.C.E. 1974. Lymphoreticular infiltration in human tumors: Prognostic and biological implications. A review. Br. J. Cancer 30: 538-548.

48. Wharton, M., Granger, D.L. and Durack, D.T. 1988. Mitochondrial iron loss from leukemia cells injured by macrophages: A possible mechanism for electron transport chain defects. $J$. Immunol. 141: 1311-1317.

49. Wink, D.A., Kasprzak, K.S., Maragos, C.M., Elespuru, R.K., Misra, M., Dunams, T.M., Cebula, T.A., Koch, W.H., Andrews, A.W., Allen, J.S. and Keefer, L.K. 1991. DNA deaminating ability and genotoxicity of nitric oxide and its progenitors. Science 254: 1001-1003.

50. Wood, G.W. and Gillespie, G.Y. 1975. Studies on the role of macrophages in the regulation of growth and metastasis of murine chemically induced fibrosarcomas. Int. J. Cancer 16: 1022-1029.

51. Xie, Q.-W., Cho, H.J., Calaycay, J., Mumford, R.A., Swiderek, K.M., Lee, T.D., Ding, A., Troso, T. and Nathan, C. 1992. Cloning and characterization of inducible nitric oxide synthase from mouse macrophages. Science 256: 225-228.

52. Xie, K., Huang, S., Dong, Z., Juang, S.H., Gutman, M., Xie, Q.W., Nathan, C. and Fidler, I.J. 1995. Transfection with the inducible nitric oxide synthase gene suppresses tumorigenicity and abrogates metastasis by K-1735 murine melanoma cells. $J$. Exp. Med. 181: 1333-1343.

53. Yim, C.-Y., Bastian, N.R., Smith, J.C., Hibbs, J.B. Jr. and Samlowski, W.E. 1993. Macrophage nitric oxide synthesis delays progression of ultraviolet light induced murine skin cancers. Cancer Res. 55: 5507-5511.

54. Yim, C.-Y., McGregor, J.R., Kwon, O.-D., Bastian, N.R., Rees, M., Mori, M., Hibbs, J.B. Jr. and Samlowski, W.E. 1995. Nitric oxide synthesis contributes to IL-2 induced antitumor responses against intraperitoneal Meth A tumor. J. Immunol. 155: 4382-4390. 